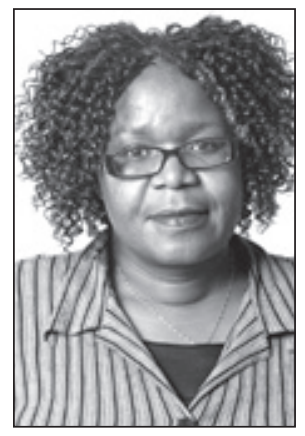

RINDAI CHIPFUNDE-VAVA

Rindai Chipfunde-Vava é diretora da organização Zimbabwe Election Support Network (ZESN). Ela é cientista política e fellow da Universidade de Stanford. Anteriormente, Rindai ocupou o posto de Coordenadora Nacional para o Zimbábue na organização Southern African Human Rights NGOS Network (SAHRINGON) e Coordenadora de Projetos na organização Zimbabwe Human Rights Association (ZimRights).

Atuou como observadora de muitas eleições em diferentes organismos da Southern African Development Community ( $S A D C$ ), assim como em outras regiões da África, Ásia, e da América.

Original em inglês. Traduzido por Muriel Soares. 


\section{ENTREVISTA COM RINDAI CHIPFUNDE-VAVA, DIRETORA DA ZIMBABWE ELECTIONS SUPPORT NETWORK (ZESN)}

Por Conectas Direitos Humanos*

Conectas realizou essa entrevista durante a participação de Rindai no IX Colóquio Internacional de Direitos Humanos que ocorreu em São Paulo, Brasil, em Novembro de 2009. Desde junho de 2007, Conectas tem facilitado a campanha inter-regional denominada Friends of Zimbabwe (Amigos do Zimbábue), composta por sete ONGs de seis países da América Latina (Argentina, Brasil, Chile, México, Peru e Venezuela). A campanha é desenvolvida em parceria com ONGs no Zimbábue, entre elas ZESN e Zimbabwe Lawyers for Human Rights (ZLHR).

Os objetivos da campanha são: (1) conscientizar diferentes setores sobre a atual situação do Zimbábue; (2) apoiar ONGs do Zimbábue, por meio da troca de experiências e do suporte às ações levadas a cabo por estas organizaçóes; (3) incidir nos governos da América latina, por meio de estratégias de lobby, para que estes pressionem e influenciem o governo do Zimbábue com vistas a restabelecer o Estado de Direito e proteger direitos humanos no país; (4) promover a cooperação entre a União Africana (UA), a Organização dos Estados Americanos (OEA) e a Organização das Nações Unidas (ONU).

Conectas: Como você começou a trabalhar no monitoramento de eleiçôes?

R: Eu iniciei a minha carreira trabalhando para uma organização de direitos humanos chamada ZimRights, no final da década de 90. Enquanto trabalhava nesta organização, tive a oportunidade de ser observadora eleitoral. Trabalhei como observadora nas eleiçóes do Malawi e percebi que mudanças eleitorais positivas estavam acontecendo, justamente por causa da presença de

* Nós gostaríamos de agradecer Rebecca Dumas pela colaboração na transcrição dessa entrevista e Tamaryn Nelson pela edição final. Original em inglês, traduzido por Muriel Soares. 
observadores. Também percebi que nada nesse sentido estava sendo feito com relação às eleiçôes no Zimbábue. E, diante dessa constatação, um grupo de organizaçóes não-governamentais criou a Zimbabwe Election Support Network (ZESN), em 2000. As eleiçôes realizadas após a sua criação foram muito contestadas, além dos riscos serem também muito altos. Estas eleições foram muito controversas porque, pela primeira vez, havia uma oposição forte Movement for Democratic Change (MDC). Isto tornou a observaçáo eleitoral ainda mais relevante, pois creio que, caso contrário, muitas irregularidades teriam passado despercebidas.

Conectas: Como é a estrutura da organização ZESN?

R: ZESN é uma organização criada no final de 1999, mas o trabalho começou efetivamente quando atuamos como observadores das eleiçóes governamentais locais em 2000. Desde então, nunca deixamos de observar eleiçóes. No que se refere à estrutura da organização, somos uma coalizão de 30 organizaçóes, que se reúnem anualmente. Há também um Conselho e um Secretariado, do qual sou a Diretora Nacional. Além da sede em Harare, temos escritórios em três províncias.

Conectas: Quais atividades a ZESN conduziu durante as últimas eleiçóes no Zimbábue?

R: Nas eleiçóes de 2008 nossa atuação foi além da simples observação eleitoral. A maioria dos grupos de observação eleitoral fazem uma contagem de votos paralela ("parallel vote tabulation", originalmente em inglês), mas nas eleiçôes do Zimbábue optamos pelo método de observação eleitoral baseado em amostras (“sample-based observation”).

A observação baseada em amostras funciona da seguinte maneira: com base em estatísticas, escolhe-se uma amostra e um time de observadores é estabelecido. Assim que os resultados são contados no centro eleitoral, estes são remetidos à central de comunicação, onde são computados e a projeção é calculada, levando-se em consideração uma certa margem de erro, níveis de confiança, entre outros fatores. Além de utilizar este método, contamos com o trabalho de dez mil observadores em nove mil sessóes eleitorais em todo o país, desta forma estávamos presentes fisicamente em praticamente todas as sessóes eleitoras do Zimbábue. Isto fez com que os zimbabuenses confiassem em nossas projeçôes. Depois que publicamos os resultados, a Comissão Eleitoral demorou um mês para publicar os resultados oficiais da eleição. Finalmente, quando os resultados foram publicados, eles estavam dentro da margem de erro e, neste sentido, as nossas projeçôes foram capazes de antever os resultados oficiais.

Essa foi a primeira vez que ZESN utilizou o método de observação eleitoral por amostra; para tanto, contratamos consultores para nos orientar. Realizamos várias pesquisas sobre o assunto e, ao final, o resultado foi bem satisfatório. Muitos países haviam utilizado essa metodologia, mas acredito que na África fomos o primeiro grupo a fazê-lo. 
Conectas: Qual aspecto foi essencial para que a observação tivesse êxito?

R: Para assegurar o sucesso do projeto é necessário um especialista em estatística, telefonistas, pessoas especializadas em Tecnologia da Informação (TI), coletores da dados, especialistas em criação de bancos de dados e um coordenador de projeto para dirigir todo o processo. Sobre equipamentos: necessita-se de um sistema de comunicação eficiente, incluindo equipamentos de telefonia por satélite, telefones celulares e carros. Isso é muito importante para a coleta de dados. Além disso, é importante contar com a ajuda de um grande número de voluntários.

Como mencionei antes, trabalhamos com um total de dez mil (10.000) voluntários. Desses dez mil (10.000), 500 estavam encarregados somente da projeção eleitoral. O time de voluntários se encarregava principalmente da comunicação, pois os resultados coletados deveriam ser anunciados 24 horas depois das eleiçôes. Os números são, em seguida, comparados com os da Comissão Eleitoral, mas queríamos divulgar as nossas projeçóes antes da publicação oficial dos resultados, justamente para evitar qualquer tipo de fraude. Assim era muito importante coletar e anunciar os resultados em 24 horas. Caso contrário, o principal objetivo de todo o projeto teria fracassado.

Conectas: Durante o Colóquio, discutimos como é difícil para defensores de direitos humanos compreenderem as eleiçóes de um país como um tema de direitos humanos. Qual sua opiniāo a respeito?

R: As eleições são um direito civil e político, e quando você olha ao redor do mundo - por exemplo, Quênia e Zimbábue - há muitas violaçôes de direitos humanos relacionadas às eleiçóes. Entre elas: tortura, espancamentos, assassinatos, desaparecimentos forçados, incêndios dolosos e assim por diante. Para mim, é a partir deste momento que as eleiçôes se tornam uma questão de direitos humanos. No Zimbábue, as eleiçóes estão muito relacionadas a violaçóes de direitos humanos. Se não fosse pelas eleiçóes, não acredito que teríamos um histórico tão ruim em direitos humanos.

Quando se olha para o histórico de crises no Zimbábue, nota-se que todas elas ocorreram durante anos eleitorais. Há diversos direitos relacionados às eleiçôes: direito à reunião, direito à associação, direito à liberdade de expressão e livre associação, e etc. Muitas vezes esses direitos são violados durante o período eleitoral e esse é o ponto chave. Eu acredito que as organizaçóes de direitos humanos devem considerar este último aspecto e incluir as eleiçóes como um dos focos do seu trabalho.

Conectas: Por que você acha que ultimamente tem aumentado a violência em muitos paises africanos depois das eleiçóes?

R: Depois da independência, muitos dos partidos políticos que haviam lutado pela libertação instauraram um sistema de partido único, por isso, nos anos 80 e 90, não havia oposiçôes. No final dos anos 90, notamos o surgimento de 
partidos de oposiçãa, como foi o caso da Zâmbia. Os países interpretaram isso como um "alerta" do fim do sistema de partido único, e decidiram "vigiar" os partidos da oposição. Consequentemente, esses novos partidos começaram a ser tratados como "inimigos" que representavam os interesses do Ocidente e que vinham para desestabilizar os partidos que haviam lutado pela libertação. Para os partidos da oposição, a única maneira de se defender era por meio do uso da violência, que eles haviam experimentado durante a luta pela libertação e não haviam esquecido. $\mathrm{O}$ resultado dessa polarização são eleições violentas em função da falta de tolerância a diferentes visóes políticas. Quando se analisa nosso sistema eleitoral, a maioria dos países usa o sistema de votação "first past the post", no qual o vencedor nas eleiçôes obtêm todo o poder e, portanto, possui o direito de formar o governo. É improvável que tenhamos um sistema de representação proporcional, no qual diversos partidos são representados no Parlamento e o poder é compartilhado entre eles.

\section{Conectas: Como você vê o papel da comunidade internacional neste contexto da polarizaçâo?}

R: No que diz respeito às eleiçóes, a comunidade internacional deveria apoiar iniciativas locais, como a participação de observadores nacionais. Ao mesmo tempo, a comunidade internacional também deveria enviar observadores internacionais para apoiar o trabalho que fazemos. Além disso, acredito que a comunidade internacional deveria financiar mais projetos relacionados à democracia, eleiçóes e capacitação dos eleitores. A capacitação eleitoral é um ponto chave. É importante que as pessoas saibam seus direitos e saibam como votar de maneira informada. Eu também acredito que, uma vez que as pessoas conhecem seus direitos, elas darão mais importância ao seu voto, inclusive no potencial de seu voto influenciar os resultados da eleição.

Conectas: E sobre o papel internacional dos paises africanos? Você acha que é possivel quebrar o padrão do voto em bloco dos paises africanos na ONU?

R: É um processo lento e depende de cada caso. Acredito que as Nações Unidas (ONU) deveriam ter uma orientação mais temática do que por país. Colocar na agenda um país como o Zimbábue, antes de discutir qualquer tema específico, faz com que outros países como China, Rússia e até a África do Sul fiquem em cima do muro. Se países específicos são colocados na agenda, eu não vejo como romper esses votos em bloco. Há também a influência do Pan-Africanismo. Precisamos de estratégias para colocar esses temas específicos na agenda das Nações Unidas.

Conectas: Na sua opinião, tendo em vista que você mencionou a China, gostariamos de perguntar qual é o papel deste país como membro da comunidade internacional, especialmente no contexto da África?

R: A China é muito presente no Zimbábue. Nós costumávamos ter países da União Européia como nossos principais investidores, mas agora temos a China. 
É uma pena que alguns países ou organizaçóes, como Commonwealth, tenham deixado de intervir nas crises do Zimbábue.

No início da crise, a União Européia seguiu uma política de não se envolver, o que deu espaço para a China vir para o Zimbábue. Não importa qual a gravidade da situação de um país, eu acho que a comunidade internacional nunca deveria deixar de se comprometer. Deveriam continuar pressionando para que outros países como a China náo monopolizem as oportunidades de investimento. Agora mesmo, China está investindo em minerais e agricultura no Zimbábue. Para mim a presença mais forte da China é um problema porque não há uma tradiçấo democrática no país. Se esses são os amigos do Zimbábue, eles serão provavelmente convidados a observar nossas eleiçōes, porém, sem terem um passado de eleiçóes justas e livres em seus próprios países. Outros exemplos são a Líbia e a Rússia. Um país deve convidar diferentes países, inclusive aqueles com históricos positivos em direitos humanos, para que possam inspecionar o processo de maneira objetiva e para que recomendam como o Zimbábue pode melhorar seu sistema eleitoral.

Conectas: Finalmente, você poderia nos dar sua opinião pessoal a respeito do indiciamento de Omar AL Bashir, presidente do Sudão, pelo Tribunal Penal Internacional?

R: Eu acredito que foi muito positivo, porque de onde eu venho há uma crença de que presidentes não podem ser acusados criminalmente. Este foi um aviso a todos os presidentes de que, se eles violarem direitos humanos, eles podem ser indiciados, pois ninguém está acima da lei. Nada mais aconteceu até então, mas eu acho que é um bom avanço. É um aviso aos atuais presidentes que violaram direitos humanos e cometeram abusos de poder. O mundo está olhando.

Sáo Paulo, 14 de novembro de 2009. 